\title{
Colégio da polícia militar Alfredo Vianna: características de uma cultura escolar-militar
}

\author{
College of the military police Alfredo Vianna: characteristics of the school- \\ military culture \\ Colegio de la policía militar Alfredo Vianna: características de una cultura \\ escolar-militar
}

\section{AMILTON GONÇALVES DOS SANTOS JOSENILTON NUNES VIEIRA}

\begin{abstract}
Resumo: O presente artigo aborda as características da Cultura Escolar de um Colégio da Polícia Militar da Bahia, considerando a integração de elementos da Cultura Militar na realidade escolar. Trata-se de uma pesquisa qualitativa que se debruçou, através de estudo de caso, sobre o contexto educacional da instituição por meio de análise documental, observações e entrevistas com gestores, docentes e alunos. Os resultados explicitaram um aparato militar objetivando a transmissão e ensino da Cultura Militar, num processo de padronização dos indivíduos por meio de uma educação do corpo e do comportamento.
\end{abstract}

Palavras-chave: Colégio da Polícia Militar. Cultura Escolar. Cultura Militar. Educação do Corpo. Educação do Comportamento.

\begin{abstract}
This article discusses the characteristics of the School Culture of a Military School of Bahia, considering the integration of elements of the Military Culture in the school reality. This qualitative research focused, through a case study, on the educational context of the institution through document analysis, observations, and interviews with managers, teachers, and students. The results made explicit a military apparatus aiming at the transmission and teaching of Military Culture, in a process of standardization of individuals through the schooling of body and behavior.
\end{abstract}

Keywords: College of the Military Police. School Culture. Military Culture. Body Education. Behavior Education.

Resumen: El presente artículo aborda las características de la Cultura Escolar de un Colegio de Policía Militar de Bahía, considerando la integración de elementos de la Cultura Militar en la realidad escolar. Se trata de una investigación cualitativa que se centró, a través de un estudio de caso, sobre el contexto educativo de la institución a través del análisis de documentos, observaciones y entrevistas con gerentes, docentes y estudiantes. Los resultados hicieron explícito un aparato militar destinado a la transmisión y enseñanza de la Cultura Militar, en un proceso de estandarización de individuos a través de la educación del cuerpo y del comportamiento.

Palabras clave: Colegio de la Policía Militar. Cultura escolar. Cultura militar. Educación del cuerpo. Educación del comportamiento. 


\section{INTRODUÇÃO}

O presente artigo aborda as relações que se estabelecem, a partir da inserção de um rol de elementos próprios da Cultura Militar na realidade de uma instituição de ensino; descreve os aspectos característicos da Cultura Escolar em um colégio da Polícia Militar da Bahia e analisa a prática pedagógica decorrente desse encontro de culturas institucionais e suas possíveis implicações na formação dos estudantes matriculados no referido estabelecimento educacional.

Trata-se de um texto elaborado a partir de uma pesquisa que deu origem a uma dissertação de mestrado defendida em 2018, no Programa de Pós-graduação em Educação, Cultura e Territórios Semiáridos da Universidade do Estado da Bahia (UNEB). A metodologia da pesquisa se baseou na abordagem qualitativa, na modalidade de estudo de caso, tendo como locus da pesquisa o Colégio da Polícia Militar Alfredo Vianna, situado na cidade de Juazeiro - Bahia.

Os dados foram obtidos por meio de análise documental, em consulta ao Regimento Escolar do Colégio da Polícia Militar da Bahia e ao Manual do Aluno; por meio de observações sistemáticas e assistemáticas bem como de entrevistas semiestruturadas ${ }^{1}$ com alunos do $3^{\circ}$ ano do Ensino Médio, gestores e professores ${ }^{2}$. A análise dos dados e informações coletadas no campo da pesquisa baseou-se nos princípios da análise de conteúdo, definida por Bardin (2011), como organização, codificação, categorização e inferência. O corpus teórico que serviu como base para as interpretações sobre o objeto de estudo se fundamenta nos conceitos e teorias existentes sobre cultura escolar e cultura militar.

Os Colégios da Polícia Militar (CPM) apresentam uma proposta escolar com características diferenciadas em metodologia, valores, finalidades, normas, organização e funcionamento. Esse contexto distinto é fruto de normativas governamentais (estaduais) que fixam um sistema de gestão compartilhada entre duas secretarias, quais sejam, a Secretaria de Educação e a Secretaria de Segurança Pública, especificamente a Polícia Militar (PM). Assim, por meio de Termos de Cooperação Técnica, que regulamentam a gestão e funcionamento dos CPM, há o compartilhamento das atividades pedagógicas, administrativas, financeiras e patrimoniais entre as referidas secretarias. Essa parceria integra às instituições não apenas o termo 'militar', mas também atividades, valores e normas, um rol de elementos próprios de instituições militares e, inclusive, Agentes Militares, que atuam profissionalmente tanto na docência quanto administrativamente.

\footnotetext{
$1 \quad$ As falas apresentadas neste estudo são oriundas de entrevistas concedidas em 2017.

2 Pela ética na pesquisa, todos os participantes assinaram termo de consentimento livre e esclarecido, tendo sua imagem resguardada pela utilização de nomes fictícios.
} 
O Sistema de Colégios da Polícia Militar, que compreende uma rede de escolas estruturadas e organizadas segundo normas próprias e comuns, é pautado numa formação cívico-militar, destinada a filhos de militares, servidores e civis, e tem chamado atenção por sua expansão nos Estados brasileiros. Segundo levantamento realizado em 2015 pela Folha de S. Paulo ${ }^{3}$, 93 estabelecimentos de ensino funcionavam em 18 Estados brasileiros baseados no modelo de gestão das Polícias Militares. Em 2017, esse número saltou para 122 unidades instaladas, com destaque para os Estados de Goiás, com 36, Minas gerais, com 26, e Bahia, com 13 (SANTOS, 2018). A expansão desse modelo escolar continua avançando, o que permite a interiorização dos CPM em várias outras regiões, situação perceptível, ao se tomar, por exemplo, o Estado de Goiás, que conta, em 2019, com $60^{4}$ unidades instaladas e em funcionamento.

O ato governamental de cooperação técnica é uma peculiaridade dessas instituições, que as diferenciam das demais escolas, civis, principalmente pela interrelação entre dois campos distintos: o Educacional e o Militar. Por essa relação, esses estabelecimentos incorporam agentes, símbolos, valores, e outros elementos da Cultura Militar que afetam diretamente o funcionamento, a gestão, as relações sociais e o cotidiano escolar, engendrando assim uma cultura singular e com características próprias. É em razão desses aspectos, desse contexto multifacetado dos CPM, que se faz pertinente discorrer sobre a Cultura Escolar-Militar.

\section{CULTURA ESCOLAR E CULTURA MILITAR: RELACIONANDO OS CONCEITOS}

As instituições escolares têm ocupado o lugar de "gestão e transmissão de saberes e símbolos" (FORQUIN, 1992, p.28), espaço de educação formal, encarregado de levar às novas gerações os conhecimentos construídos socialmente. Ao mesmo tempo, também são dotadas de um caráter dinâmico, criativo e multifacetado que se apresenta nas práticas cotidianas, da vida e do fazer escolar e deles resulta. Nesse sentido, os estudos sobre a escola não podem excluir as características do seu funcionamento.

Assim, para captar as características que possibilitam compreender o funcionamento da escola, é preciso então levar em consideração a práxis da escola, sua Cultura Escolar, produto cultural da capacidade criativa da escola (CHERVEL, 1990), a qual pode ser compreendida como resultado de todas as ações humanas

\footnotetext{
3 Informações disponíveis em: http://www1.folha.uol.com.br/educacao/2015/08/1666631-crsceno-brasil-o-numero-de-escolas-basicas-piblicas-geridas-pela-pm.shtml. 
no ambiente escolar: toda prática escolar é cultura (BENITO, 2017; SILVA, 2009). A noção de Cultura Escolar permite incluir não apenas as estruturas pesadas e reprodutivas da escola, mas também seus sujeitos, os comportamentos, os conhecimentos, os espaços, as relações conflituosas ou pacificas, as práticas e normas (JULIA, 2001; VIÑAO, 2006).

Para Julia (2001, p.10), um dos primeiros autores a discorrer sobre o conceito, Cultura Escolar se configura como "um conjunto de normas que definem conhecimentos a ensinar e condutas a inculcar, e um conjunto de práticas que permitem a transmissão desses conhecimentos e a incorporação desses comportamentos".

Em linhas semelhantes, Antonio Viñao (2006) considera Cultura Escolar como o conjunto de teorias, ideias, princípios, normas diretrizes, rituais, inércias, hábitos e práticas sedimentados ao longo do tempo sob a forma de tradições e regras e compartilhado por seus atores no interior das instituições de ensino. Assim posto, a Cultura Escolar permite dirigir o olhar para o interior dos processos escolares, para o estudo das questões escolares como as relações entre os diferentes atores, os ritos, os procedimentos, tradições, costumes e as normas. A Cultura Escolar centra-se na perspectiva do próprio ambiente escolar.

Vinão (2006) também nos apresenta um elemento pertinente ao introduzir a ideia de 'culturas institucionais' como referência às culturas produzidas por outras instituições distintas, sejam de caráter educacional (de níveis diferentes, pública ou privada), governamental, político, religioso, etc., além também da cultura dos professores e da sala de aula, dos alunos e das famílias ou pais, que se incorporam à Cultura Escolar como produto dos tipos de alinhamento com a instituição de ensino. Assim, embora cada estabelecimento educacional detenha sua própria Cultura Escolar, esta carrega traços culturais que a caracteriza e distingue das demais (VIÑAO, 2006, p.80).

Segundo Dussel (2014. p.261), "a cultura escolar abriu caminho para a noção de culturas escolares plurais". Essa acepção faz alusão às culturas específicas de cada escola que, inclusive, conduzem Viñao a utilizar a expressão Culturas Escolares, no plural, na qual cada escola é detentora de sua própria cultura. De certo, as definições de cultura escolar referem-se claramente a uma variedade de elementos culturais (ELÍAS, 2015, p. 290). Nessa mesma linha, Escolano Benito (2000; 2017) advoga a existência e interação de diversos tipos de culturas da escola e elenca ao menos três: a cultura empírico-prática, construída pelos professores no exercício da sua profissão; a cultura científica, constituída pelos especialistas e pelos conhecimentos acadêmicos; a cultura política, de origem políticoinstitucional e engloba os administradores e burocratas que regulam e gerenciam os sistemas e instituições educacionais. 
Escolano Benito (2000; 2017), ao argumentar sobre a cultura política, concede bases para explorar as relações que se estabelecem nos CPM (instituições criadas por meio normativo político-institucional) a partir do alinhamento entre os campos educacional e militar, permitindo a incorporação de traços da Cultura Militar à instituição escolar. Segundo Sousa (2015, p.16), a Cultura Militar pode ser definida como "um conjunto de valores, costumes, tradições e base conceptual que ao longo do tempo se tornaram o caráter da profissão militar". Trata-se de uma cultura que deriva de determinadas características esperadas dos militares, como comportamento, lealdade, honra, respeito, trabalho em equipe, dever altruísta, e dos valores que suportam esses elementos, tais como a hierarquia e a disciplina.

A Cultura Militar não circunscreve apenas um aspecto cultural profissional; não apenas define uma profissão, ela produz uma identidade militar, expressando, assim, nos sujeitos um estilo de vida, um modo de ser diário e cotidiano (SILVA, 2012). É uma cultura que padroniza, tornando homogêneo o comportamento, o pensar, as práticas e os uniformes, sob a tutela de um mesmo regulamento. Por fim, a Cultura Militar é fruto de uma tradição secular, construída, ensinada e transmitida por diferentes instituições militares e permeada por teorias e tradições militares bem como pelo aspecto político.

\section{O CPM ALFREDO VIANNA: UMA BREVE CONTEXTUALIZAÇÃO}

$\mathrm{Na}$ Bahia, a partir do Decreto $\mathrm{n}^{\circ} 16.765$, assinado pelo governador Antônio Balbino e publicado no Diário Oficial do Estado em 09/04/1957, regulamentou-se a criação do primeiro Colégio da Polícia Militar da Bahia - Unidade Dendezeiros, em Salvador. Na mesma data, o Boletim Geral $^{5}$ da Polícia Militar documentava a fundação de uma "instituição escolar secundária, pública, gratuita, militarizada e destinada aos filhos (do sexo masculino) dos policiais militares e de outros funcionários públicos" (JESUS, 2011, p.51). Anos mais tarde, em 1998, é criado mais um colégio, o CPM, Unidade Lobato, também em Salvador. Entre os anos de 2005 e 2007 novas unidades foram criadas, alcançando o número de 13 instituições em funcionamento, garantindo a expansão e interiorização dos CPM em todo o Estado. É nesse cenário que, em 2006, é criado o CPM Alfredo Vianna em Juazeiro-BA.

5 Conforme Jesus (2011), os Boletins (BG/O e BI/O) funcionavam como documentos legais e institucionais no contexto da Corporação de Polícia Militar, com características semelhantes aos Diários Oficiais. 
Segundo histórico disponível no sítio oficial da Polícia Militar, antes da transformação em Colégio Militar, a instituição teve suas atividades iniciadas em 1972, sob o nome de Centro Integrado Alfredo Vianna, contemplando o ensino de $1^{\circ}$ a $4^{\circ}$ série. Em 1985, a partir da Portaria n 10080, o estabelecimento passou a se chamar Escola de $1^{\circ}$ Grau Alfredo Vianna, contemplando agora o ensino de $1^{\circ}$ a $8^{\circ}$ série. Somente em 2006, por meio de Termo de Cooperação Técnica, firmado entre as Secretarias de Educação e Segurança Pública (Polícia Militar) do Estado, a instituição foi transformada em Colégio da Polícia Militar Alfredo Vianna (CPMAV), atendendo a alunos dos Ensinos Fundamental e Médio.

O sistema de gestão compartilhada entre as secretarias, firmado pelo Termo de Cooperação Técnica, celebrado através do Convênio nº 018/2015 e reafirmado pela Portaria Conjunta SEC/SSP/PM nº 01 de 17/03/2015, dáse através de um Colegiado Diretor (instância de deliberação administrativa, financeira e pedagógica das unidades escolares) composto por um Diretor designado por cada uma das secretarias.

O funcionamento e todas as atividades desenvolvidas no CPM se dá em consonância com a Diretriz Educacional nº 001 de 2016, documento instituído pelo Instituto de Ensino e Pesquisa da Polícia Militar (IEP), que define o Regimento Escolar dos Colégios da Polícia Militar da Bahia. O regimento escolar, dividido em sete títulos e um anexo, expressa as finalidades, valores e princípios, bem como a estrutura organizacional e didática, a forma de ingresso, as normas de convivência, disciplinares e de promoção.

A forma de ingresso na instituição se dá por meio de sorteio eletrônico, embora, em seu primeiro ano de funcionamento, as vagas tenham sido definidas por meio de seleção. Obedece a um determinado percentual de vagas por série, sendo $50 \%$ para filhos de militares, servidores civis e professores e outros $50 \%$ para filhos de civis. Conforme o IEP, em 2017, a quantidade de alunos matriculados somava 714, sendo 181 filhos de militares, 2 de servidores e 531 de civis. Percebe-se que, apesar do percentual reservado para filhos de militares, a maioria das vagas era preenchida por civis. Seu corpo docente era composto por 36 civis e 25 militares (Policiais Militares, designados pelo Diretor PM, através do IEP e detentores de formação acadêmica exigida para o exercício da docência, segundo Regimento Escolar, sendo o cumprimento da função custeado pela Secretaria de Segurança Pública). O exercício da docência para os militares habilitados contempla as funções de Instrutor e Monitor, sendo este último Praça PM que auxilia ou substitui o Instrutor. Já o quadro administrativo do CPMAV apresentava 16 civis e 34 militares (Policiais Militares). 
O CPMAV, em 2018, teve seu local de funcionamento alterado, passando a desenvolver suas atividades não mais na antiga instituição que lhe conferiu o nome, operando então nas instalações do Colégio Polivalente Américo Tanuri, que enterra seu patrimônio histórico-cultural-educacional de décadas e cede lugar ao CPM que ainda carrega seu nome de origem e passa a contar com uma estrutura maior e capaz a receber mais alunos.

\section{AS CARACTERÍSTICAS DE UMA CULTURA ESCOLAR-MILITAR}

A concretização do convênio que cria o CPMAV engendra uma singularidade que diferencia essa instituição das demais escolas civis públicas ou privadas. Trata-se do seu modelo de gestão partilhada, um caráter sui generis, que normatiza a entrada da Cultura Militar na instituição e confere uma inter-relação das esferas Escolar-Militar, permitindo a penetração de uma gama de elementos militares na vida escolar, os quais são prescritos por um conjunto de normas e regulamentos. Dentre essas normas, o Regimento Escolar dos Colégios da Polícia Militar da Bahia constitui um interessante documento de análise e explicita seu caráter militar, inclusive ao confirmar sua singularidade pelas características de proposta pedagógica específica voltada para, além das suas atribuições legais e regularmente definidas, a formação cívico-militar própria da PM da Bahia.

Oreferido documento, para além da definição da estrutura e funcionamento dos CPM, expressa também sua identidade militar, principalmente pela presença e quantidade de expressões de características militares: a palavra "Militar" (e suas variações) é mencionada 168 vezes; os termos "Normas" e "Comportamento" aparecem 54 e 50 vezes, respectivamente; a expressão "Disciplina” (e suas variações) é explicitada 117 vezes, dentre as quais 29 fazem referência à matéria (conteúdo de ensino ou área do conhecimento) e na Seção III, Das Normas Disciplinares (onde estão prescritas as transgressões, as punições e penalidades), se repetem 38 vezes.

Pela força das normas, a Cultura Militar penetra a escola, integrandose e deixando sua marca na gestão escolar, na construção do currículo, nas práticas docentes, na sala de aula, na divisão dos espaços e do tempo, nas relações interpessoais e nas atividades dentro e fora da escola, inclusive com a inserção de órgãos da Polícia Militar, bem como de um corpo específico de profissionais (policiais) incumbidos da garantia e efetividade do que está regulamentado. Nessas instituições, desenvolve-se uma educação profundamente regulamentada, que normatiza práticas, comportamentos e saberes, fazendo-os singulares pelo estabelecimento de uma "hierarquia" de valores militares sobre os civis. 
Ao destacar a presença de elementos militares nos documentos estudados, não podemos perder de vista que "os textos normativos devem sempre nos reenviar às práticas” (JULIA, 2001, p.19) e como normas e práticas são coordenadas em relação a determinadas finalidades. A Cultura Escolar não se refere somente a normas, mas também a práticas que induzem comportamentos e produzem configurações múltiplas e variadas no espaço escolar (DUSSEL, 2014; MUNAKATA, 2016). Nesse sentido, estudar normas juntamente com as práticas nos permite compreender os processos educacionais que se estabelecem na instituição. Assim, partindo do estudo de normas e práticas, com base nos dados coletados, duas características de escolarização ficaram evidentes: uma que atua sobre o corpo e outra sobre o comportamento dos indivíduos.

\section{CONTROLE SOBRE A LINGUAGEM E A ESTÉTICA CORPORAL}

Considerando que o corpo se expressa nas interações humanas, enquanto linguagem utilizada nos processos comunicacionais (WEIL; TOMPAKOW, 2015), nesta seção buscou-se descrever e analisar os dispositivos característicos da Cultura Escolar do CPMAV utilizados para moldar e uniformizar os comportamentos a partir do controle sobre as expressões do corpo.

Durante as visitas de observação, previstas na metodologia da pesquisa, buscou-se conhecer a rotina escolar da instituição. Numa delas, logo pela manhã, por voltas das 06h15min., os alunos, que começavam a chegar - uns de carro, outros de bicicleta ou a pé - aglomeram-se em frente ao colégio, na calçada ou encostados em árvores. Às 06h20min a entrada foi liberada, sendo o ingresso à instituição condicionado à apresentação da carteira estudantil. No portão, um Policial Militar, devidamente fardado, fiscaliza e controla o fluxo dos alunos, deixando à parte àqueles com pendências no fardamento e que não apresentaram a carteira estudantil.

Nas dependências do colégio, as salas de aula, laboratórios e salas administrativas formam um quadrado, sendo seu interior o pátio e, no centro deste a cantina. Os estudantes deixavam seus materiais nas salas de aula e voltavam ao pátio para as atividades do dia. Uma sirene soou às $06 \mathrm{~h} 45 \mathrm{~min}$; era o aviso que sinalizava para os alunos entrarem 'em forma' e iniciar a parada matinal.

A parada matinal diz respeito às revistas ao corpo discente e compreende, além das atividades militares, a verificação do uniforme, da apresentação pessoal, do cabelo e acessórios, dentre outros elencados no Regimento Escolar e no Manual do Aluno. Os alunos iam tomando posição, agrupando-se por série, em pé e enfileirados, organizando-se inclusive pela distância entre os corpos. Via ali, na prática, uma "parada militar", características da Cultura Militar, elementos 
próprios de instituições militares, uma organização dos espaços, uma disciplina dos movimentos, uma padronização dos uniformes, um respeito a símbolos da pátria e da corporação militar.

Uma aparelhagem de sonorização estava montada, e a Aluna do $\mathrm{Dia}^{6}$, aparentemente nervosa, toma posse de um microfone e comanda as ações: "Atenção! Silêncio! Sentido!". A ordem é entendida e imediatamente os movimentos se igualam, os corpos postam-se eretos, as pernas fechadas, os braços alongados para o chão e as mãos (espalmadas) vão sobre as coxas. A aluna dirige-se ao Coordenador do Corpo de Alunos ${ }^{7}$, presta continência, identifica-se pelo nome e número de matrícula e solicita autorização para iniciar as atividades.

Após permissão concedida pelo coordenador, e sob o comando da Aluna do Dia, os demais alunos, enfileirados e em posição de sentido, passam a entoar o Hino da Independência da Bahia. Nesse momento, inspetores PM circulam entre as turmas verificando se todos entoam o hino, conferem o alinhamento e a postura. Ao finalizar o canto, a Aluna do Dia dá a ordem: "Descansar!". A postura dos alunos muda, as pernas abrem ao nível dos ombros, enquanto os braços voltam-se para trás.

O Coordenador toma a palavra e discursa sobre a disciplina e os valores do CPMAV, enfatizando que o desrespeito às normas não é tolerável e finaliza: “aqui não é a casa da Tia Sassá!". Em seguida passa a palavra para a Aluna do Dia que brada: "sentido; descanso; sentido; descanso!". Os estudantes obedecem às ordens de comando com seus corpos treinados, alternando movimentos e posturas. Finalizando, as turmas são informadas que o deslocamento às salas darse-ia do ano inferior ao mais alto $\left(9^{\circ}\right.$ ano do Ensino Fundamental, $1^{\circ}, 2^{\circ}$ e $3^{\circ}$ ano do Ensino Médio) e seguem as últimas ordens: "direita; volver; volver; esquerda, volver".

A obediência a esses comandos se constitui uma técnica corporal específica, tradicional e eficaz: são “Técnicas do Corpo" (MAUSS, 2003). Para o autor, a expressão reflete as maneiras como os homens sabem servir-se, de forma tradicional, do seu corpo. Portanto, há uma técnica do corpo, um ato de ordem mecânica, física ou físico-química que é efetuado com esse objetivo (MAUSS, 2003, p.407), mas vejam, há também uma “educação do corpo", ensino de técnicas do corpo que possibilitam certas aprendizagens.

\footnotetext{
$6 \quad$ Função designada a um estudante do $3^{\circ}$ ano do Ensino Médio, cujo objetivo é desenvolver o senso de responsabilidade e liderança.

7 Órgão da corporação militar do Estado da Bahia, responsável por estruturar, planejar e executar as ações de caráter pedagógico voltado para a formação militar.
} 
Uma análise dos documentos evidenciou que a educação do corpo compete à disciplina de Instrução Militar, componente da matriz curricular do CPMAV, a qual, objetiva promover a assimilação da Cultura Militar e da cultura policial militar por parte dos alunos, bem como despertar o gosto e a vocação pela carreira militar, sendo seu exercício de responsabilidade de Inspetores e Monitores PM. Nessa disciplina, os alunos aprendem sobre os movimentos corporais de modo a reconhecerem e obedecerem uniformemente os comandos de uma tradição militar incorporada pela escola. Assim, o ensino-aprendizagem de um conjunto de práticas corporais vivenciadas na escola visa a adaptar o corpo às expectativas individuais e institucionais por meio do movimento ordenado dos corpos que se submetem ao controle determinado pela ação pedagógica.

Enquanto disciplina do currículo da escola, a Instrução Militar prescreve e define o que se quer desses corpos e como se quer. Por outro lado, enquanto prática, ela materializa e permite a transmissão e incorporação dos conhecimentos e práticas corporais desejadas, utilizando-se de técnicas operacionais para 'adestrar', moldar, governar e produzir corpos homogêneos. Um elemento específico da Cultura Militar que permite a eficácia da institucionalização e incorporação desses mecanismos normativos e práticos é a disciplina.

A disciplina constitui um gerenciamento e controle sobre os corpos, incidindo sobre seu funcionamento, bem como no tempo e espaço, individualizando-os, e, por sua vez, ela "fabrica indivíduos" (FOUCAULT, 1987). Ela é dotada de um poder de controle que opera sobre o corpo, impondo uma obediência, uma relação de docilidade útil e em conformidade com um 'regime de legalidade'. No CPMAV, o regime de legalidade é representado pelas normas disciplinares, especificadas no Regimento Escolar e no Manual do Aluno, que se utiliza de elementos coercitivos da punição e penalização como dispositivos de segurança contra transgressão e desvio do modelo prévio, determinado e padrão. O dispositivo da punição é um agente inibidor que atua para impedir o erro disciplinar e manter a obediência pelo medo. Assim, estabelece-se uma noção de infra-penalidade, como coloca Foucault (1987, p.149):

\footnotetext{
$\mathrm{Na}$ essência de todos os sistemas disciplinares funciona um pequeno mecanismo penal. É beneficiado por uma espécie de privilégio de justiça, com suas leis próprias, seus delitos especificados, suas formas particulares de sanção, suas instâncias de julgamento. As disciplinas estabelecem uma 'infra-penalidade'; quadriculam um espaço deixado vazio pelas leis; qualificam e reprimem um conjunto de comportamentos que escapava aos grandes sistemas de castigo por sua indiferença.
} 
As técnicas de sujeição do corpo, habituais na Cultura Militar, são incorporadas à dinâmica pedagógica da escola, tornando-se um caráter habitual pela repetição e reprodução diária das suas práticas. A rotina, o hábito, institucionaliza as práticas, cristalizando-as e corporificando-as na vida escolar, ao tempo que se instituem como certos, normais e naturais. Assim, quanto mais tempo os alunos convivem com esses mecanismos, mais eficaz é a assimilação e inculcação dos valores e normas oriundas do meio militar, imprimindo fortes marcas na cultura escolar.

O controle da linguagem corporal não abarca apenas a postura, os movimentos, os gestos e ações do corpo; ela inclui também um aspecto visual, da aparência, que nos permite falar de uma 'estética corporal'. As definições normativas instituem as vestimentas, os calçados, os acessórios, o corte de cabelo e penteado, a maquiagem, cor e tamanho da unha; por meio de permissões e proibições, fixam uma padronização, uma uniformização dos corpos. Por outro lado, na prática, representa uma estética da aparência, cujo objetivo é comunicar e identificar os corpos, formatar e criar iguais, apagar, assim, as diferenças.

O Regulamento de Uniformes, prescrito no Manual do Aluno, reforça essa estética corporal ao definir o 'código de vestuário' da instituição que, diferente das escolas civis, não permite variantes além do previsto como calçados, calças e camisas de outros tipos, cores e modelos. Há diferentes uniformes e cada um está relacionado a um evento ou atividade específica, mas, para além de uma vestimenta, eles carregam uma identidade militar, pois transmitem os elementos e significados próprios de instituições militares. O fardamento identifica o aluno, sua patente, tipo sanguíneo, seriação, a instituição e seu Estado de origem, características que o definem como elemento material e cultural do CPAMV, um artefato de comunicação, como advogam Ribeiro e Silva (2012).

Enquanto artifício de comunicação, o uniforme também conforma uma ideia de igualdade. Segundo a Coordenadora, "o fardamento padrão exclui a concepção de diferença de classes, pois todos possuem a mesma vestimenta, desde o tipo de tênis até as demais roupas" (Relato de entrevista). Porém, o que se observou foi um "sistema de igualdade formal" (FOUCAULT, 1987), uma igualdade estética que difere do real, principalmente pela dificuldade de alguns alunos em adquirir o fardamento por falta de condições financeiras, o que leva a escola a realizar campanhas para doação de uniformes por parte daqueles estudantes que têm uma melhor situação econômica. 
A estética corporal é esse culto à apresentação pessoal. Ela faz invisíveis as diferenças, diminui a visibilidade do heterogêneo e atinge as individualidades, padronizando o feminino e o masculino. Pela estética, o uniforme é inviolável, deve estar limpo e passado, com fivela no cinto, sapatos e coturnos polidos, sendo proibido aos alunos fixar ou pendurar óculos, broche ou distintivo.

Sobre o corpo a estética define distinções, segmentando o masculino e o feminino. Ao primeiro fica proibido raspar a cabeça ou tingir o cabelo, bem como o uso de topete, costeleta e bigode. Ao feminino é vedado o uso: de esmaltes em cores fortes (preto, vermelho, violeta, etc.); de brincos em apenas uma orelha ou mais de um em cada orelha, bem como argolas e pingentes; de anéis com pedras de cor e não podendo ser colocado no polegar; de presilhas coloridas; de maquiagem em excesso ou em cores chamativas. Outras proibições são dirigidas a todos, como a proibição de lentes de contato diferentes da sua cútis, óculos de sol, pulseiras, fitas, tornozeleiras, piercing e argolas, aparelho celular, dentre outros.

Constatou-se até aqui que o controle sobre a linguagem e a estética do corpo permite a incorporação individual de elementos da Cultura Militar e, coletivamente, faz-se homogênea. Assim, há um controle absoluto do corpo que invisibiliza as diferenças, formatando, uniformizando e padronizando os indivíduos, resultando na formação de Alunos PM's. Eis o que se apresenta: uma instituição que, para além do ensino formal, desenvolve um ensino da Cultura Militar, uma formação militar. Tem-se, pois, uma escolarização que, pelo imperativo da disciplina, forma indivíduos obedientes. Mas, a eficácia da cultura militar não está apenas na educação do corpo, ele perpassa também uma modelagem do comportamento.

\section{MODELAGEM DO COMPORTAMENTO}

A militarização de escolas representa a inter-relação entre a escola e culturas exteriores a ela (BENITO, 2017), destacando-se aqui a cultura militar. $\mathrm{Na}$ prática, essa interatividade das culturas escolar e militar proporcionou uma metamorfose na realidade e no cotidiano da instituição pesquisada, a partir da incorporação de normas e práticas militares ao ambiente de educação escolar, representando um processo de "hibridação cultural" (VIDAL, 2006, p.159). Nessa relação cultural escolar/militar, desenvolve-se um ensino cívico-militar, no qual se observa um controle sobre a linguagem do corpo, como já destacado, mas também, uma modelagem do comportamento.

A modelagem do comportamento compreende uma educação específica,

que se desenvolve por meio de métodos, técnicas, critérios, estratégias e instrumentos, os quais permitem o ensino e transmissão de conhecimentos 
direcionados à formação de determinado padrão de comportamento. Trata-se de uma educação cujo imperativo é formar pessoas cujo comportamento, a conduta, o caráter, a moral e os hábitos dos indivíduos se pautem pela obediência aos padrões normativos instituídos.

O desenvolvimento dessa educação no CPMAV se institui com normas e práticas formativas próprias da cultura militar, com destaque para o controle sobre a linguagem corporal e padronização do comportamento dos discentes. Assim, o conjunto de normas e práticas objetivam o ensino, a transmissão e a incorporação de condutas e comportamentos específicos (JULIA, 2001), princípios doutrinários da formação militar.

A efetivação do modelo de comportamento padrão se dá pela repetição de rituais cotidianos, que visam a formar o sujeito dócil e convencido da sua necessidade de adaptação às intempéries naturais e sociais e, ao mesmo tempo, habituados a desafiar seus limites físicos e intelectuais em busca da superação. Essa intencionalidade do ato educativo desenvolvido na instituição pesquisada é demonstrada no Regimento Escolar, o qual prescreve uma deontologia estudantil, que faz referência ao conjunto de deveres estabelecidos em código específico aos quais os alunos estão submetidos e impõe a cada integrante do CPMAV uma conduta moral, irrepreensível e adequada a qualquer espaço social, permitindo que os indivíduos levem para a vida os valores apreendidos, o respeito às leis, às normas e aos regulamentos.

A análise do regimento mostra uma educação do comportamento e um controle deste, por meio da quantificação, mensuração e classificação, ao estabelecer graus de conduta que variam de 0 a 10 , divididos em seis níveis: excepcional (10); ótimo (9 a 9,99); bom (7 a 8,99); regular (5 a 6,99); insuficiente (2 a 4,99); e incompatível (abaixo de 2). Na prática, o valor atribuído ao comportamento do estudante é que define sua permanência ou não no CPMAV.

Outro documento analisado, o Manual do Aluno do CPMAV, explicita pormenorizadamente os elementos à formação da conduta militar. Ele prescreve e regula a conduta diária dos alunos, dentro e fora da instituição, discorrendo sobre o permitido e o proibido. Praticar o proibido, o não permitido ou vedado, é ingressar no comportamento incompatível, na prática de indisciplina, numa "irreverência que desacata as normas estabelecidas" (HECKERT; ROCHA, 2012, p.88). Não é por acaso que os referidos termos perpassam os 76 artigos do documento, sendo que "proibido (a)" aparece 17 vezes; "não é permitido", seis vezes; e "vedado" é descrito 14 vezes, sendo nove apenas no segmento feminino. Assim, toda conduta contrária ao modelo instituído é 'anormal', à medida que todo aluno CPM carrega a personificação militar e deve zelar pelo nome da instituição e da Polícia Militar, de tal forma que seu comportamento deverá ser 
exemplar e modelo para os demais. Não se trata apenas de cumprir a norma; há de ser exemplo, como expressa o slogan do CPMAV: 'A palavra convence, o exemplo arrasta'.

Ser exemplo é resultado da educação do comportamento e representa a obediência às regras que definem o modelo prévio de conduta. A garantia dessa obediência está atrelada, em grande parte, ao instrumento militar da disciplina que, assim como na educação do corpo, exerce o controle sobre a conduta dos indivíduos. A disciplina age regulamentando tudo acerca da instituição e, enquanto elemento da Cultura, opera sobre a realidade escolar impedindo a prática do 'anormal' e o comportamento indisciplinado, exercendo seu controle por meio de um regime de legalidade - Normas Disciplinares do CPMAV - que penaliza o infrator e coercitivamente, pelo medo, inibe a prática da transgressão disciplinar. Acerca da prática da penalização, o Professor "E" se expressa da seguinte forma: “o aluno sabe quando ele está infringindo o regimento. Ele tem consciência quando tá infringindo uma regra, e o professor ele tem a quem se reportar pra que aquele aluno seja penalizado quando ele tá atrapalhando a aula, quando ele comete algum erro de ordem disciplinar" (Relato de entrevista).

Segundo o Regimento Escolar, transgressão disciplinar é qualquer violação à ética, aos deveres e obrigações escolares, às regras de convivência social e aos padrões de comportamento impostos aos alunos e são classificadas em quatro naturezas: leve, média, grave e eliminatória. Contudo, nem todas as transgressões implicam a perda de pontos de comportamento, algumas são convertidas em punição alternativa ou castigos.

O primeiro contato com a prática de punição ocorreu quando me retirava da sala de direção, após entrevista com o Diretor Sec. Já no pátio, observava vários alunos em forma, organizados em fila, sob o sol das 10:00 h e uma temperatura próxima aos 35 graus. Pelas indicações no uniforme, percebi que todos eram alunos do $2^{\circ}$ ano. $\mathrm{O}$ comandante do Corpo de Alunos discursava, repreendendoos pela prática de comportamento incompatível. Aproximou-se de mim o Chefe de Setor. Explicava que a turma estava cumprindo punição de dez minutos por indisciplina em sala de aula que impossibilitou o desenvolvimento das atividades docentes. Denunciados pelo professor, todos foram punidos, porque cada um é responsável pela ordem em sala de aula, de modo que quem comete conduta irregular seja repreendido tanto pelo Xerife ${ }^{8}$, quanto pelos demais alunos. Para o Chefe de Setor, esse tipo de penalização constitui punição alternativa, um "castigo" que não incide em perda de pontos por comportamento incompatível.

Função conferida aos alunos que, escalados semanalmente, são encarregados de zelar pela disciplina, pelo material e pelo bom andamento das atividades em sala, bem como delatar quaisquer ocorrências de indisciplina. 
Nessas passagens, puderam-se destacar características da educação do comportamento, desde o aspecto da fiscalização, que impõe a todos uma estrutura de vigilância, um sistema de câmeras oculares organizado com a finalidade de vigiar e controlar as condutas. Todas essas características explicitadas atuam coercitivamente sobre a conduta dos discentes e, principalmente, pelo medo da punição, concebem condições de governabilidade à instituição, assegurando o bom funcionamento do estabelecimento e a aparência de bem-estar dos indivíduos.

Os efeitos da disciplina e controle sobre a conduta destacam-se também em sala de aula. Nas cadeiras organizadas em filas, os alunos devem estar sentados e manter a limpeza da mesma. O silêncio é obrigatório e as conversas paralelas são proibidas. Os discentes devem manter total atenção à aula, permitindo que o ensino flua sem interrupções. Quaisquer desvios de comportamento são denunciados tanto pelo Xerife, quanto pelo professor. Os docentes recebem o status de oficial, um tipo de personificação militar, um estatuto simbólico que confere uma relação diferenciada com seus alunos. Todos devem respeito ao professor, prestando-lhe continência e respondendo-o por Senhor. "Boa tarde, Senhor!"; bradavam os alunos ao receber o docente em sala, que os respondia com um "descansar!". Essa personificação militar também está expressa na fala do Diretor PM: “o aluno ao entrar na sala de aula ele lá também é olhado pelo professor, mesmo o professor civil - dentro de colégio militar ele tem prerrogativa de oficial. Lá dentro é idêntico a um policial militar que estivesse ali ministrando aquela aula" (Relato de entrevista).

Os relatos explicitados foram úteis para demonstrar como a educação do comportamento, a partir da Cultura Militar, é responsável pela conduta dos indivíduos, utilizando-se de atividades e conteúdos que passaram a representar um campo fértil e útil ao ambiente escolar. Destaca-se também a presença de instrumentos coercitivos como um conjunto de normas disciplinares que, pelo medo, impõe um controle sobre a conduta, a qual é reafirmada por uma disciplina militar que fundamenta a obediência ao regulamentado e responde pelas diversas faces e características da Cultura Militar. Além disso, ainda expressa o papel do corpo militar como legitimador da cultura, dos valores, dos conhecimentos, das práticas, da identidade e conduta militar. Os Policiais são os guardiões da ordem institucionalizada e assumem o papel de fiscalizadores do comportamento padrão, atuando para que os indivíduos incorporem as normas, sendo obedientes e tornando possíveis as práticas.

Além dos aspectos apresentados, a educação da conduta ultrapassa os muros do CPM e deixa suas marcas também na instituição família; isso porque os pais, ao matricularem seus filhos, assumem o compromisso de auxiliar no cumprimento dos regulamentos necessários à permanência no colégio. Esse 
contexto ficou claro ao se observar a presença constante dos pais na escola que, na maioria das vezes, estava associada ao comportamento incompatível, à indisciplina e à conduta anormal dos alunos, como também pela ausência escolar não comunicada. Por esses fatores, o Corpo de Alunos convoca a presença dos responsáveis para comunicação das faltas cometidas e recebimento de justificativas.

Todo o aparelho militar é posto e desenvolvido como artefato de formação à conduta militar, mas não circunscreve apenas a educação do corpo e do comportamento; ele explicita, como observado nos documentos institucionais, o pensamento militar, um aparato de componentes necessários à admiração pela carreira militar e inculca nos indivíduos o sentimento de respeito e admiração pelas instituições militares, seus valores e cultura, despertando-lhes a vocação para a profissão Policial Militar. Familiarizados e adaptados à rotina militar, a partir da educação do comportamento, como do corpo, os alunos passam a almejar a profissão militar.

Pelo exposto, podemos afirmar que a Cultura Escolar do CPMAV, com a incorporação da Cultura Militar, opera na conformação de uma conduta padrão e de uma moral a qual ela mesma ajudou a criar, moldando e normalizando o indivíduo em comportamento e caráter através de normas e práticas, inculcandolhes "valores e virtudes morais, normas de civilidade, o amor ao trabalho, o respeito pelos superiores, o apreço pela pontualidade, pela ordem e pelo asseio" (BARBOSA, 2011, p.7).

\section{CONSIDERAÇÕES FINAIS}

No estudo, constatou-se a inter-relação entre os campos Educacional e Militar resultante do caráter político-normativo da cooperação técnica que institui os CPM. Por essa dualidade, evidenciou-se a existência de um hibridismo cultural que representa a interação entre diferentes culturas no âmbito escolar, dentre estas a Cultura Militar, característica da cultura política, de origem políticoinstitucional. A partir dessa interação, há uma institucionalização da Cultura Militar na realidade da instituição. Primeiro, pela incorporação de um corpo de Agentes Militares e uma seara de elementos do campo militar, tais quais valores, símbolos, vestimentas, normas, práticas e conhecimentos. Segundo, pela pedagogização e transmissão dessa cultura que, por meio de instrumentos e métodos distintos, permite o ensino de comportamento e conduta específica, apreendida e inculcada pelos indivíduos.

O resultado desse rol de elementos militares, desse aparato militar na vida escolar é uma educação específica que atua na promoção dos aspectos militares, objetivando a transmissão e ensino da Cultura Militar. Identificou-se então, 
alicerçado nos dados, uma educação do corpo e do comportamento que detém um controle sobre a linguagem e estética corporal, bem como uma modelagem do comportamento, cuja finalidade é padronizar e homogeneizar os corpos e condutas dos indivíduos.

Essa educação permite a formação de indivíduos conforme padrão desejado e utiliza de uma disciplina militar e um regime de legalidade pautado em normas de comportamento e conduta que prescreve castigos e punições pelo seu descumprimento. Atrelado a isso, há o acompanhamento fiscalizador dos profissionais militares que, em conjunto com os demais instrumentos de controle, permite a eficácia na transmissão da Cultura Militar. Assim, padronizam-se os indivíduos, apagando as diferenças e fabricando alunos obedientes e também aptos à carreira militar.

O estudo permitiu concluir que a Cultura Militar está diariamente no fazer escolar, nas atividades diárias, nos corpos e comportamentos, nas práticas e normas, inserida e preservada na estrutura de funcionamento do CPM. Assim, pela incorporação e apropriação de uma seara de características militares, define-se a "genética cultural" da instituição, engendrando seu próprio patrimônio cultural e estabelecendo uma Cultura Escolar-Militar.

\section{REFERÊNCIAS}

BAHIA (Estado). Decreto $n^{\circ}$ 16.765, de 09 de abril de 1957. Dispõe sobre a criação do Colégio Estadual da Polícia Militar. Diário Oficial do Estado da Bahia, Bahia, 09 de abril de 1957.

BAHIA (Estado). Instituto de Ensino e Pesquisa. Diretriz Educacional n 001, de 15 de janeiro de 2016. Aprova o Regimento Escolar dos Colégios da Polícia Militar da Bahia e dá outras providências. Disponível em: http://www.pm.ba. gov.br/images / files / REGIMENTO\%20INTERNO\%20DOS\%20CPM.pdf. Acesso em: 27 de jul. 2019.

BAHIA (Estado). Secretaria da Educação do Estado da Bahia. Secretaria de Segurança Pública da Bahia. Convênio n 018/2019. Termo de Cooperação Técnica que entre si celebram a Secretaria da Educação e a Secretaria da Segurança Pública, com interveniência da Polícia Militar da Bahia. Diário Oficial do Estado da Bahia, Bahia, 20 de mar. 2015. Seção 1, p.13. 
BAHIA (Estado). Secretaria da Educação do Estado da Bahia. Secretaria de Segurança Pública da Bahia. Portaria Conjunta SEC/SSP/PM Nº1 de março de 2019. Institui instâncias de gerenciamento nas unidades estaduais sujeitas a Convênio de Cooperação Técnica entre a Secretaria da Educação e a Secretaria da Segurança Pública do Estado da Bahia. Diário Oficial do Estado da Bahia, Bahia, 20 de mar. 2015. Seção 1, p.13.

BARBOSA, Ellen Borges. Reflexos do pensamento de Foucault na constituição da Cultura Escolar Brasileira. Revista Pandora Brasil - Edição especial n ${ }^{\circ} 4$ "Cultura e materialidade escolar" - 2011.

BARDIN, Laurence. Análise de conteúdo. Trad. Luís Antero Reto, Augusto Pinheiro. São Paulo: Edições 70, 2011.

BENITO, Agustín E. A Escola como Cultura: experiência, memória e arqueologia. Tradução e revisão técnica: Heloísa Pimenta Rocha, Vera Lúcia Gaspar da Silva. Campinas, SP: Editora Alínea, 2017.

- Las Culturas Escolares del siglo XX. Encuentros y desencuentros.

Revista de Educación, num. Extraordinário, 2000, p.201-218.

CHERVEL, A. História das Disciplinas Escolares: reflexões sobre um campo de pesquisa. Teoria e Educação, Porto Alegre, v.2, 1990, p.177-229.

DUSSEL, Inés. A montagem da escolarização: discutindo conceitos e modelos para entender a produção histórica da escola moderna. Revista Linhas, Florianópolis, v.15, n.28, p.250-278, jan./jun., 2014.

ELÍAS, M. E. La cultura escolar: Aproximación a um concepto complejo. Revista Electrónica Educare, vol.19(2), mayo-agosto, 2015, p.285-301.

FORQUIN. Jean-Claude. Saberes escolares, Imperativos didáticos e dinâmicas sociais. Teoria e Educação, Porto alegre, v.5, 1992, p.28-49.

FOUCAULT, Michel. Vigiar e Punir: o nascimento da prisão. Trad. de Raquel Ramalhete. Petrópolis, RJ: Vozes, 1987. 
HECKERT, Ana Lúcia Coelho; ROCHA, Maria Lopes da. A Maquinária Escolar e os Processos de regulamentação da Vida. Psicologia \& Sociedade, 24, p.8593, 2012.

JESUS, Andrea Reis de. Colégio Estadual da Polícia Militar - Primeiros Tempos: formando brasileiros e soldados. 2011, 156f. Dissertação (Mestrado em Educação) - Faculdade de Educação, Universidade Federal da Bahia, Salvador, 2011.

JULIA, D. A Cultura escolar como objeto histórico. Revista Brasileira de História da Educação, Campinas, n.1, 2001, p.9-45.

MAUSS, Marcel. As técnicas do corpo. In: Sociologia e Antropologia. São Paulo: Cosac \& Naify, 2003, p.399-422.

MUNAKATA, Kazumi. Livro Didático como indício da Cultura Escolar. História da Educação, Porto Alegre, v.20, n50, set./dez., 2016, p.119-138.

RIBEIRO, Ivanir; SILVA, Vera Lúcia Gaspar da. Das Materialidades da Escola: o uniforme escolar. Educação e Pesquisa, São Paulo, v.38, n³ 3 , p.575-588, jul./ set., 2012.

SANTOS, Amilton Gonçalves dos. A Cultura Escolar no Colégio da Polícia Militar Alfredo Vianna - Juazeiro/BA. 2018. 196 f. Dissertação (Mestrado em Educação, Cultura e Territórios Semiáridos) - Universidade do Estado da Bahia, Juazeiro/BA. 2018.

SILVA, Agnaldo. Praça Velho. Socialização, representações e práticas policiais militares. Goiânia: PUC-GO, 2012.

SILVA, Mônica Ribeiro da. Reformas Educacionais e Cultura Escolar: A apropriação dos dispositivos normativos pelas escolas. Cadernos de Educação, FaE/PPGE/UFPel, Pelotas, 32, p.123-139, janeiro/abril, 2009.

SOUSA, Simão Pedro da Costa de. A Cultura Nacional e a Cultura Militar. 2015. 89 f. (Trabalho de investigação Individual) - Instituto de Estudos Superiores Militares, Pedrouço, 2015. Disponível em: HTTPS://comum.rcaap. pr/handle/10400.26/10131. Acesso em: 27 de jul. 2019. 
VIDAL, Diana Gonçalves. Cultura e práticas escolares: a escola pública brasileira como objeto de pesquisa. Historia de La Educación, 25, 2006, p.153-171.

VIÑAO, Antonio. Sistemas educativos, culturas escolares y reformas. $2^{\circ} \mathrm{Ed}$. Madrid: Morata, 2006.

WEIL, Pierre; TOMPAKOW, Roland. O corpo fala: a linguagem silenciosa da comunicação não verbal. 74 ed. Petrópolis: Vozes, 2015.

AMILTON GONÇALVES DOS SANTOS é Mestre em Educação, Cultura e Territórios Semiáridos (2018) e Graduado em Pedagogia (2009) pela Universidade do Estado da Bahia (UNEB) - DCH III. Especialista em Docência do Ensino Superior (2013) pela Universidade Cândido Mendes. Membro do Grupo de Estudos e Pesquisas em História da Educação e Pedagogia da Pesquisa - GEPHEPP e do Grupo de Pesquisa em Educação, Desenvolvimento e Profissionalização do Educador - UNEB. Atualmente é Servidor Efetivo da Universidade Federal do Vale do São Francisco - UNIVASF.

E-mail: amilton.santos@univasf.edu.br.

ORCID: https://orcid.org/0000-0003-3841-9723

JOSENILTON NUNES VIEIRA é Doutor em Educação pela Universidade Federal do Rio Grande do Norte (2009), Mestre em Educação pela Universidade Federal da Bahia (2002) e Graduado em Pedagogia pela Universidade do Estado da Bahia (1993). Atualmente é Professor Adjunto na Universidade do Estado da Bahia no Curso de Pedagogia e no Programa de Pós-Graduação em Educação, Cultura e Territórios Semiáridos. É também Professor Titular da Autarquia Educacional do Vale do São Francisco / Faculdade de Ciências Aplicadas e Sociais de Petrolina - AEVASF/FACAPE e Professor Colaborador no Programa de Pós-Graduação Mestrado Profissional em Formação de Professores e Práticas Interdisciplinares - PPGFPPI.

E-mail: vieirajn47@gmail.com.

ORCID: https://orcid.org/0000-0002-3415-1099

Recebido em agosto de 2019

Aprovado em setembro de 2019 